\title{
Chronic Pelvic Abscedation After Completion Proctectomy in a Rectal Stump Insufficiency; Treatment With Gracilis Muscle Flap Following Vacuum Assisted Closure Therapy
}

\author{
Fatma Ayca Gultekin, Bekir Hakan Bakkal ${ }^{1}$, Sait Tayfun, Orhan Babuccu², Mustafa Comert \\ Departments of General Surgery, ${ }^{1}$ Radiation Oncology, and ${ }^{2}$ Plastic, Reconstructive and Aesthetic Surgery, BulentEcevit University School of \\ Medicine, Zonguldak, Turkey
}

Presacral abscess formation due to rectal stump insufficiency following Hartmann procedure is very rare complication. If the abscess cavity is large, it might delay the reversal of the stoma and will probably result in a devastating future functioning of the neorectum. Moreover, very invasive treatments will be required in order to prevent severe septic complications. We present the case of a 58-year-old man with a past history of Hartmann procedure for a low rectal carcinoma who presented with rectal stump insufficiency and a large presacral abscess. Following extensive debridement and rectal stump resection, a vacuum-assisted closure (VAC) system was applied to the large abscess cavity to facilitate gracilis muscle flap reconstruction and to optimize wound healing. The satisfactory results showed in the present report led us to favor a combination of VAC therapy and a gracilis muscle flap in intrapelvic and perineal reconstruction in the case of large defects associated with high risks of septic complications.

Keywords: Rectal; Stump; Insufficiency; Negative-pressure Wound therapy; Pedicled flap

\section{INTRODUCTION}

Insufficiency of a rectal stump after Hartmann procedure is a serious and feared complication following colorectal surgery and is associated with early and long-term morbidity and mortality. Mostly, a presacral abscess occurs following insufficiency of a rectal stump. The small abscess can potentially be treated by taking a wait-and-see approach. A large abscess requires additional surgical procedures and long-term drainage of the abscess cavity. The presence of prolonged pelvic sepsis and the inefficiency of secretion drainage have rarely resulted in perineal extirpation of the rectum. Resection of the rectum and anus from the pelvis creates

Received: October 4, 2012 - Accepted: January 5, 2013

Correspondence to: Fatma Ayca Gultekin, M.D.

Department of General Surgery, BulentEcevit University School of Medicine, Kozlu, Zonguldak 67600, Turkey

Tel: +90-372-2613201, Fax: +90-372-2610155

E-mail: faycagultekin@yahoo.com

(c) 2013 The Korean Society of Coloproctology

This is an open-access article distributed under the terms of the Creative Commons Attribution NonCommercial License (http://creativecommons.org/licenses/by-nc/3.0) which permits unrestricted noncommercial use, distribution, and reproduction in any medium, provided the original work is properly cited. a large cavity that is fixed by using surrounding pelvic bony structures. This pelvic dead space results in an accumulation of fluid and blood clot that increases the risk of developing a pelvic abscess, a wound infection, and perineal wound sinus tracts. Vacuum-assisted closure (VAC, Kinetic Concept Inc., San Antonio, TX, USA) is a procedure where suction is applied via open-cell foam. The VAC system involves placing a foam sponge on or into the wound and applying a controlled subatmospheric pressure [1]. This leads to removal of fluid and edema from the wound, which, in turn, increases local blood flow, reduces the bacterial load, and stimulates growth of granulation tissue [2]. Although the VAC system has been proven to speed up healing in different types of wounds, persistent wound failure likely mandates surgical intervention and may require placement of a well-vascularized, nonirradiated tissue flap on a large defect or placement of a skin graft on a clean granulating wound. We report a case of chronic pelvic abscedation following a complete proctectomy, with consistent mucopurulent secretion from the perineum, which was successfully treated with a combination of VAC-therapy and a gracilis muscle flap. 
Volume 29, Number 4, 2013

\section{CASE REPORT}

A 58-year-old man underwent Hartmann procedure for obstructed lower rectal cancer at another hospital in September 2011. Pathological findings at that time indicated a stage IIIB tumor that had infiltrated beyond the muscularis propria into pericolorectal tissues with three lymph nodes showing metastases (pT3N1M0). The patient underwent chemoradiotherapy; weekly, 5-fluorouracyl $\left(500 \mathrm{mg} / \mathrm{m}^{2}\right)$ and folinic acid $\left(500 \mathrm{mg} / \mathrm{m}^{2}\right)$ were administered over 6 weeks as one cycle. After two cycles of chemotherapy, chemoradiotherapy was administered using the intensity-modulated radiation therapy technique to a dose of 50.4 Gy radiation after the surgery. The patient was referred to our division for reversal of the Hartmann procedure on January 2012. However, he had complained of intermittent periods of fever and perineal pain since his surgery and lately had suffered from purulent secretion through the anus. The top of the rectal stump was palpated about 4 to $5 \mathrm{~cm}$ from the anal verge, but it had irregular borders and was hardened. Also, a hole was palpated at the tip of the rectal stump. During the digital examination, about $80 \mathrm{~mL}$ of pus and mucus evacuated through the anus, and a decreased anal sphincter tonus was found. Endoscopy revealed a short rectal stump just $2 \mathrm{~cm}$ above the dentate line, as well as a disruption and a draining hole centered on the top of the stump. The opening was wide enough to allow the introduction of the scope into the abscess cavity, which measured $6 \mathrm{~cm} \times 3 \mathrm{~cm}$ and was filled with necrotic material (Fig. 1). Magnetic resonance imaging showed a large presacral collection of $7 \mathrm{~cm}$ and some osteonecrotic changes of the sacrum.

The adjuvant radiotherapy, the short rectal stump and the poor anal sphincter tonus increased the risk of bad functional outcome; therefore, we decided to perform a complete proctectomy with VAC. The rectal resection was performed, and the perineal

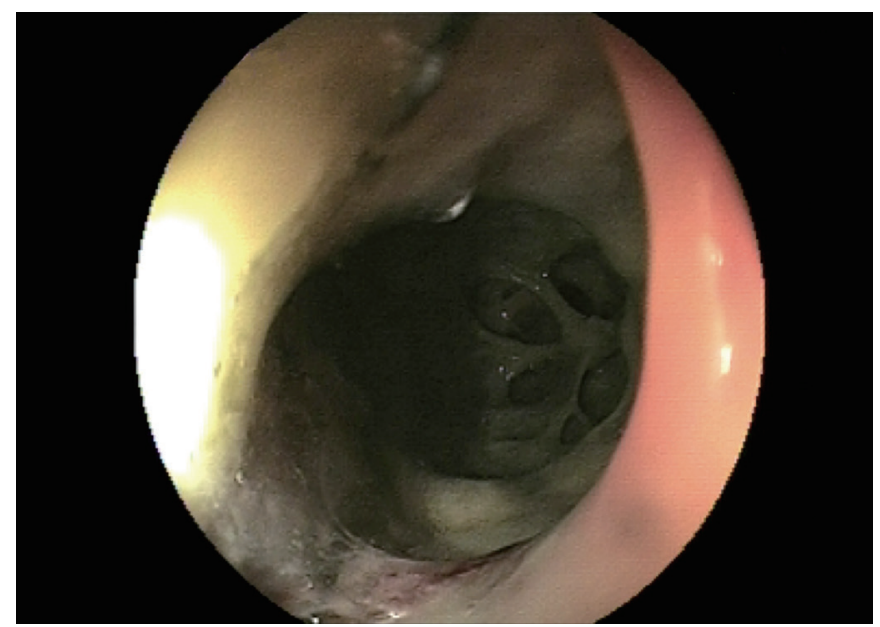

Fig. 1. Endoscopic view of a draining hole centered on top of the rectal stump; pus and fibrotic tissues are seen in the abscess cavity. The length of the abscess cavity is $6 \mathrm{~cm}$. cavity was left open, but was packed with four rolls of gauze in order to ensure perineal hemostasis prior to putting the VAC system in place. The pack was removed one day later, and the VAC system was set in place (the wound measured $10 \mathrm{~cm} \times 15 \mathrm{~cm}$, Fig. 2) under general anesthesia and set at a $125-\mathrm{mmHg}$ depression (Type of foam: VAC GranuFoam Medium Dressing Kit, Kinetic Concept Inc.). Owing to the considerable pain and the position of the wounds, the VAC system had to be reapplied in theater 3-times a week initially, which was later reduced to twice weekly. Sequential wound assessment demonstrated marked improvements with visible granulation tissue following the application of the VAC system set at a $125-\mathrm{mmHg}$ continuous topical negative pressure (Fig. 3). The amount of fluid was $200 \mathrm{~mL}$ every day during the first five days and decreased to $10 \mathrm{~mL}$ during the last two days. Three weeks later, a significant reduction in the wound size

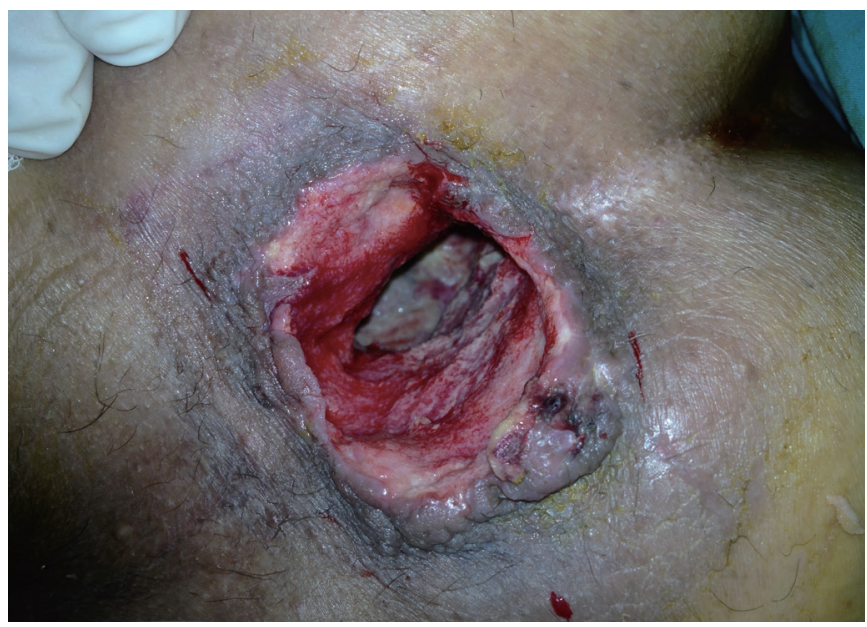

Fig. 2. Perineal defect after completion of a proctectomy and debridement.

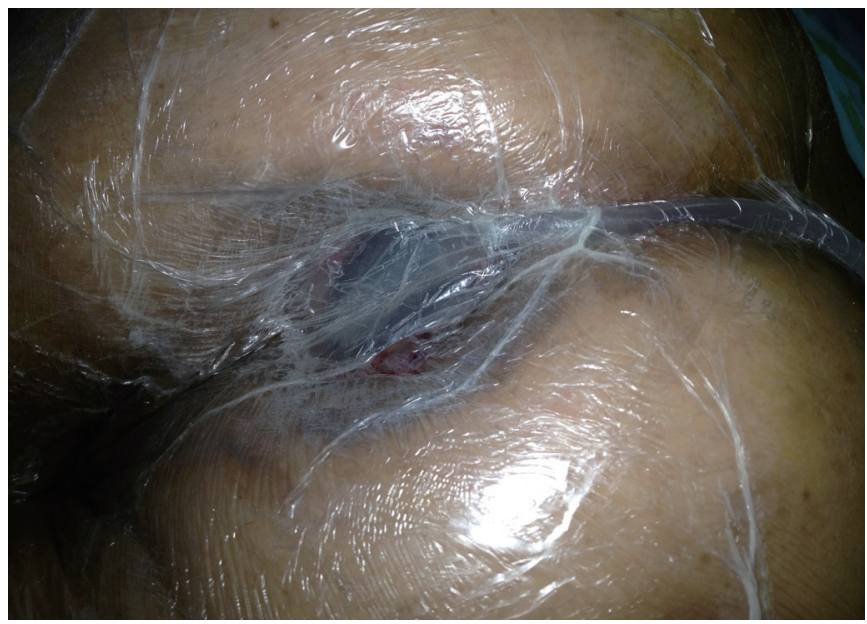

Fig. 3. Placement of the vacuum-assisted-closure system relative to the perineal wound. 


\section{$\begin{aligned} \text { Annals of } & \begin{array}{l}\text { Chronic Pelvic Abscedation After Completion Proctectomy in a Rectal Stump Insu } \\ \text { Treatment With Gracilis Muscle Flap Following Vacuum Assisted Closure Therapy }\end{array}\end{aligned}$}

\section{Coloproctology Fatma Ayca Gultekin, et al.}

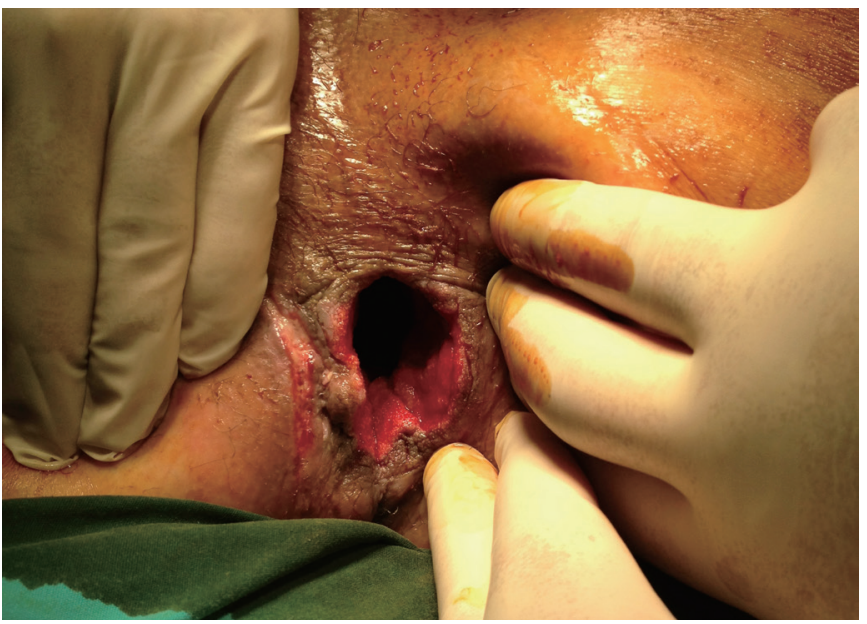

Fig. 4. Perineal wound after 28 days of vacuum-assisted-closure therapy at $125 \mathrm{mmHg}$.
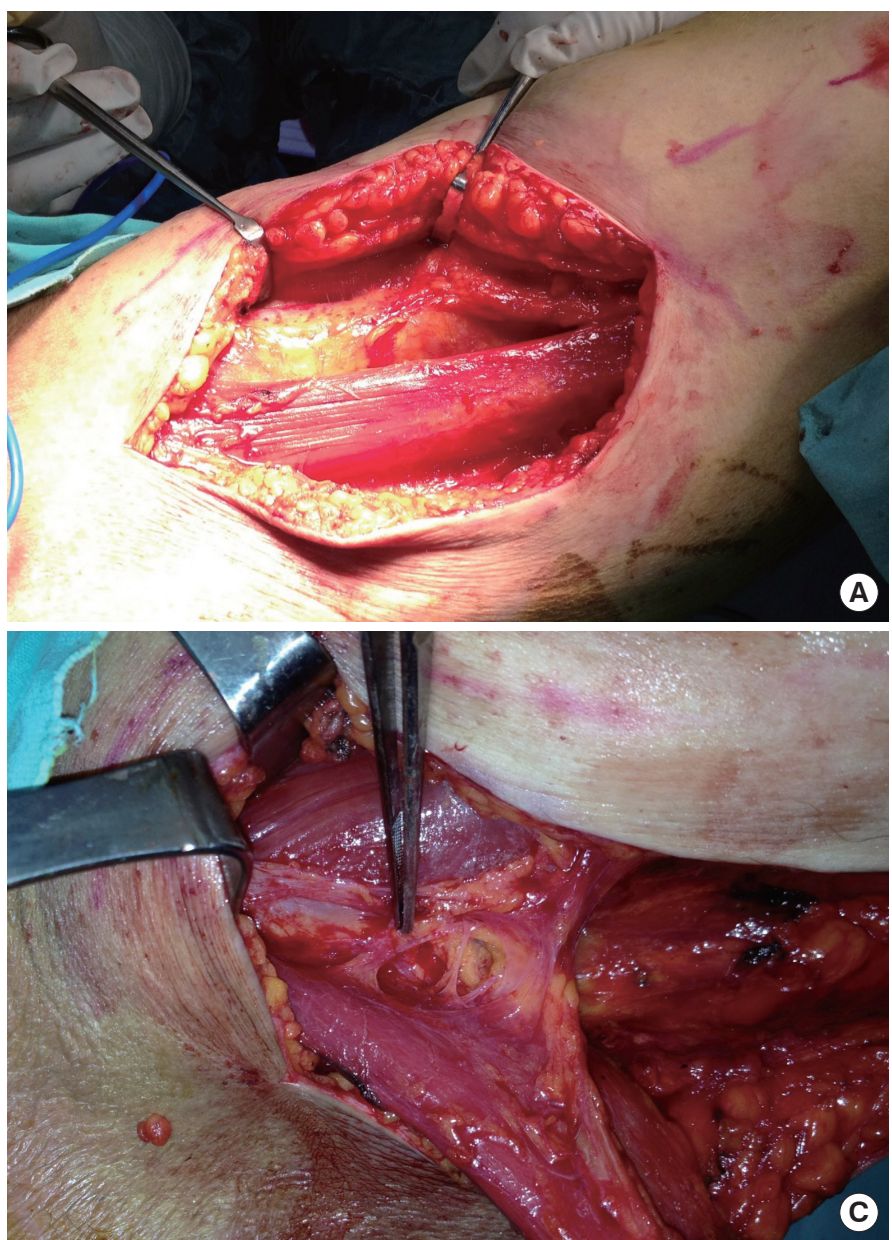

(5 $\mathrm{cm} \times 6 \mathrm{~cm}$, Fig. 4) was evident, and on day 28, VAC therapy was stopped because the size of the cavity was no longer decreasing. However, the remnant of the cavity was still large, and fibrosis prevented apposition of the remaining soft tissue structures. Thus, we decided to filled the cavity with a gracilis muscle flap. The muscle flap were obtained from the left thighs' gracilis muscle and was then positioned within the bulk of the pelvic dead space, and the perineum was reconstructed. First, the muscle flap was taken from the detached gracilis muscle containing the medial circumflex femoral artery, vein, and nerve to promote better blood supply to the flap. The flap was then rotated in the direction of the sacrum and sutured (Fig. 5). A suction drain was placed on the left thigh, and the perineum was closed with primary sutures. Although a postoperative sinus developed in the perineal wound, a good blood supply prevented graft failure, and the sinus closed spontaneously in a short period. Two months after the gracilis muscle flap transposition, the perianal wound was completely healed.
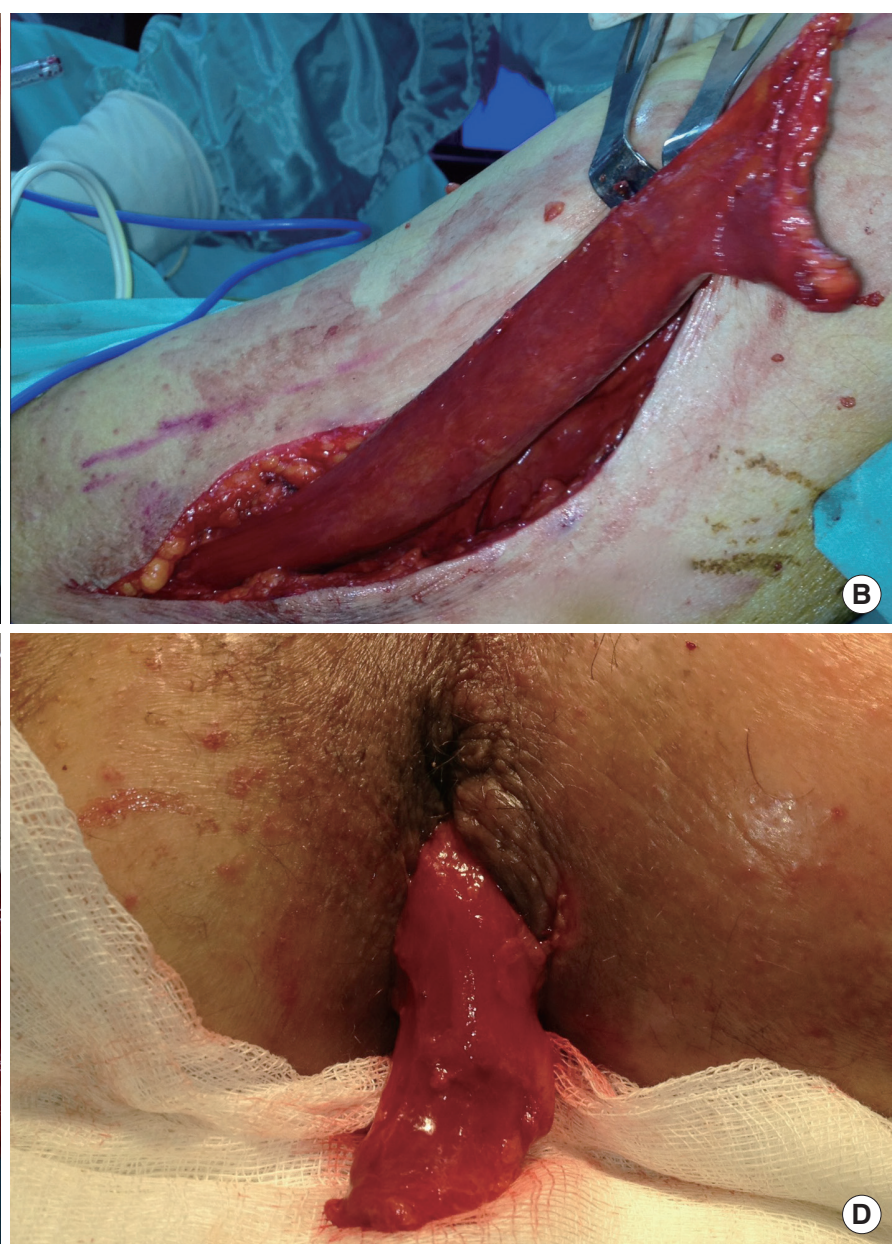

Fig. 5. (A) Identification and isolation of the gracilis muscle at the medial side of the left thigh. (B) Mobilization of the gracilis muscle following dissection of the distal part. (C) The most proximal neurovascular pedicle is preserved. (D) The muscle flap is tunneled subcutaneously and fixed into position in the presacral space in order to reach the pelvic area. 


\section{DISCUSSION}

Although insufficiency of a rectal stump after a Hartmann procedure is a very rare occurrence, incidence rates as high as $14 \%$ have been reported [3, 4]. However, risk factors such as operative technique, pelvic radiation and indication for surgery (i.e., rectal cancer, anal cancer, or inflammatory bowel disease) are strong predictors of this complication. Management of rectal stump insufficiency is similar to management of anastomotic leakage after surgery. A general approach to small anastomotic leakages after surgery in the pelvic area can potentially be treated by a wait-and-see approach. This is not the case when the leakage involves a significant part of the circumference. This frequently leads to a large presacral sinus, which often requires additional surgical procedures and long-term drainage of the abscess cavity [5]. It has been recently reported that an endo-sponge-assisted closure can be used alternatively in the treatment of colorectal anastomotic leakage [6-8]. An endo-sponge is inserted into the pararectal abscess cavity. Through the application of a controlled negative pressure, a cleaning and shrinking of the wound can be achieved. A few available case studies using this technique have reported success rates up to $90 \%$ [9]. Although several successful application of endo-sponge-assisted closure are reported in the literature in the case of rectal stump insufficiency [10], it has been found to be ineffective in patients with a wide-open stump [11]. Therefore, an endo-sponge might be of less value for the treatment of rectal stump insufficiency. Interestingly, in the current literature, hardly any recommendations exist on how to deal with rectal stump leaks. Following rectal stump resection, our patient developed a large abscess in the minor pelvis, with a nonhealing perineal wound. The ideal treatment should control pelvic sepsis and should speed up healing and closure of the presacral cavity. As endo-sponge treatment will not work in large, open perineal defects, regular VAC treatment was applied to our patient. Although VAC therapy provided infection control and relative shrinkage of the abscess cavity and perineal defect, surgical resection of the rectum still left a large cavity within the irradiated pelvis. Muscle flaps transfer healthy unirradiated tissue into an irradiated pelvis and give sufficient bulk of tissue to cover pelvic dead space [12].

Although a number of recent reports have described the usefulness of vertical rectus abdominis musculocutaneous (VRAM) flap transposition $[12,13]$, the VRAM flap limits colostomy placement or resiting in the future should the primary site suffer from a significant complication [13]. Therefore, in our case, we performed a gracilis muscle flap transposition. The major advantages of using the gracilis muscle are primarily related to its avoidance of interfering with the creation of a colostomy site. The flap is particularly useful in small defects that are relatively narrow and distal in the pelvis. Disadvantages include a high incidence of precarious vascularity, smaller muscle mass with decreased effectiveness in large perineal defects and pelvic dead space, and high susceptibility to vascular spasm and cutaneous skin paddle ischemia [13].
In view of the data, the management of large tissue defects in pelvic regions by means of the VAC method, as a temporary coverage positively supports wound conditioning, reduces infectious complications and facilitates a definitive wound closure. However, in the case of a large pelvic cavity or perineal defects, muscle or myocutaneous flaps improve wound-healing VAC therapy. This case serves to demonstrate that a combination of VAC therapy and the use of a gracilis flap may be useful in complicated perineal wounds in an irradiated pelvis. The advantages and the disadvantages of the various methods of reconstruction need to be carefully evaluated to reduce the risk of postoperative complications. Further investigations are required to confirm our observations.

\section{CONFLICT OF INTEREST}

No potential conflict of interest relevant to this article was reported.

\section{REFERENCES}

1. Argenta LC, Morykwas MJ. Vacuum-assisted closure: a new method for wound control and treatment: clinical experience. Ann Plast Surg 1997;38:563-76.

2. Morykwas MJ, Argenta LC, Shelton-Brown EI, McGuirt W. Vacuum-assisted closure: a new method for wound control and treatment: animal studies and basic foundation. Ann Plast Surg 1997; 38:553-62.

3. Bakker FC, Hoitsma HF, Den Otter G. The Hartmann procedure. Br J Surg 1982;69:580-2.

4. Gallot D, Jauffret B, Goujard F, Deslandes M, Sezeur A, Malafosse M. Hartmann's procedure: a retrospective study of 86 cases. Ann Chir 1992;46:491-6.

5. van Koperen PJ, van Berge Henegouwen MI, Rosman C, Bakker CM, Heres P, Slors JF, et al. The Dutch multicenter experience of the endo-sponge treatment for anastomotic leakage after colorectal surgery. Surg Endosc 2009;23:1379-83.

6. Glitsch A, von Bernstorff W, Seltrecht U, Partecke I, Paul H, Heidecke CD. Endoscopic transanal vacuum-assisted rectal drainage (ETVARD): an optimized therapy for major leaks from extraperitoneal rectal anastomoses. Endoscopy 2008;40:192-9.

7. Mees ST, Palmes D, Mennigen R, Senninger N, Haier J, Bruewer $\mathrm{M}$. Endo-vacuum assisted closure treatment for rectal anastomotic insufficiency. Dis Colon Rectum 2008;51:404-10.

8. Nagell CF, Holte K. Treatment of anastomotic leakage after rectal resection with transrectal vacuum-assisted drainage (VAC). A method for rapid control of pelvic sepsis and healing. Int J Colorectal Dis 2006;21:657-60.

9. Weidenhagen R, Gruetzner KU, Wiecken T, Spelsberg F, Jauch KW. Endoscopic vacuum-assisted closure of anastomotic leakage following anterior resection of the rectum: a new method. Surg Endosc 2008;22:1818-25.

10. Riss S, Stift A, Kienbacher C, Dauser B, Haunold I, Kriwanek S, et 


\section{Coloproctology Fatma Ayca Gultekin, et al.}

al. Recurrent abscess after primary successful endo-sponge treatment of anastomotic leakage following rectal surgery. World J Gastroenterol 2010;16:4570-4.

11. Riss S, Stift A, Meier M, Haiden E, Grunberger T, Bergmann M. Endo-sponge assisted treatment of anastomotic leakage following colorectal surgery. Colorectal Dis 2010;12(7 Online):e104-8.

12. Chan S, Miller M, Ng R, Ross D, Roblin P, Carapeti E, et al. Use of myocutaneous flaps for perineal closure following abdominoperineal excision of the rectum for adenocarcinoma. Colorectal Dis 2010;12:555-60.

13. Wiatrek RL, Thomas JS, Papaconstantinou HT. Perineal wound complications after abdominoperineal resection. Clin Colon Rectal Surg 2008;21:76-85. 